\title{
Beyond the critical period: longitudinal study of 8-year outcome in first-episode non-affective psychosis
}

Niall Crumlish, Peter Whitty, Mary Clarke, Stephen Browne, Moayyad Kamali, Maurice Gervin, Orfhlaith McTigue, Anthony Kinsella, John L. Waddington, Conall Larkin and Eadbhard O'Callaghan

\section{Background}

The critical period hypothesis proposes that deterioration occurs aggressively during the early years of psychosis, with relative stability subsequently. Thus, interventions that shorten the duration of untreated psychosis (DUP) and arrest early deterioration may have long-term benefits.

\begin{abstract}
Aims
To test the critical period hypothesis by determining whether outcome in non-affective psychosis stabilises beyond the critical period and whether DUP correlates with 8-year outcome; to determine whether duration of untreated illness (DUI) has any independent effect on outcome.
\end{abstract}

\section{Method}

We recruited 118 people consecutively referred with first-episode psychosis to a prospective, naturalistic cohort study.

\section{Results}

Negative and disorganised symptoms improved between 4 and 8 years. Duration of untreated psychosis predicted remission, positive symptoms and social functioning at 8 years. Continuing functional recovery between 4 and 8 years was predicted by DUI.

\section{Conclusions}

These results provide qualified support for the critical period hypothesis. The critical period could be extended to include the prodrome as well as early psychosis.

\section{Declaration of interest}

None. Funded by the Stanley Medical Research Institute.
The critical period hypothesis proposes that the early phase of psychosis, including any period of initially untreated psychosis, is a 'critical period' during which symptomatic and psychosocial deterioration progresses rapidly. Afterwards, progression of morbidity slows or stops, and the level of disability sustained, or recovery attained, by the end of the critical period endures into the long term. ${ }^{1}$

The critical period hypothesis has underpinned the development of services specialising in early intervention in psychosis in the UK and elsewhere, ${ }^{2-4}$ but some have argued that services dedicated to early intervention 'for an arbitrary "critical period" of a few years' waste scarce resources. ${ }^{5}$ Moreover, the critical period is still a hypothesis, with two testable central premises. The first is that outcomes stabilise beyond the critical period and a few longitudinal studies have reported stability ensuing 2-5 years after the onset of psychosis. ${ }^{6,7}$ The second is that untreated initial psychosis is associated with increasing debilities in the medium to long term, and researchers differ on this issue as to whether outcome was measured in the first year, ${ }^{8,9}$ after 2 years $^{10-13}$ or up to 15 years after presentation. ${ }^{14,15}$ No single study has tested both central premises.

In this study we assessed a cohort with first-episode psychosis at presentation, 4 years later and 8 years later. We tested the critical period hypothesis by determining whether outcome stabilised between 4 and 8 years and duration of untreated psychosis (DUP) correlated with 8-year outcome. Additionally, as the influence of duration of untreated illness (DUI) has been debated from the dawn of the first-episode psychosis era ${ }^{16}$ to the present day, ${ }^{13,17,18}$ we examined whether DUI had a relationship with 8-year outcome distinguishable from that of DUP.

\section{Method}

\section{Setting and participants}

The sample consisted of 118 participants in a prospective, naturalistic inception cohort study of first-episode psychosis in south-east Dublin, Ireland. We recruited all people with firstepisode psychosis consecutively referred to the Cluain Mhuire Service and St John of God Hospital, Dublin, between February 1995 and February 1999. ${ }^{8,18}$ Cluain Mhuire is a geographically defined catchment area service, providing community-based psychiatric care for an urban population of 165000 . Patients of Cluain Mhuire requiring admission are admitted to St John of God Hospital. Both out-patients and in-patients were recruited to the study. We defined first-episode psychosis as a first presentation to any psychiatric service with a psychotic episode. People who had started taking antipsychotic medication in another setting prior to referral were included as long as treatment had been ongoing for less than 30 days.

The 118 individuals discussed in this paper are those who received at presentation a DSM-IV diagnosis of non-affective psychosis: schizophrenia, schizophreniform disorder, delusional disorder or psychotic disorder not otherwise specified; no cases of brief psychotic disorder were identified. ${ }^{19}$ We included people with a history of substance misuse, but excluded those with substance-induced psychosis. The lower age limit for entry into the study was 12 years. There was no upper age limit.

This study was approved by the research ethics committee of the Hospitaller Order of St John of God. Verbal consent was obtained from each participant at presentation. The assessment 
process received approval from the research ethics committee as a best practice procedure, so every person meeting the criteria for inclusion was included in the study at presentation. We assessed each person with a broad range of standardised clinical measures at presentation, 4 years later and 8 years later. At 8 -year follow-up, we obtained written informed consent from all participants.

\section{Measures}

\section{Presentation assessments: 1995-1999}

As soon as possible after first presentation, we measured psychopathology and insight with the Positive and Negative Syndrome Scale (PANSS). ${ }^{20}$ When participants were clinically stable, we diagnosed each person and obtained demographic information using the Structured Clinical Interview for DSM-IV (SCID). ${ }^{21}$ We completed the Global Assessment of Functioning (GAF), which is Axis V of the SCID. We assessed quality of life with the Quality of Life Scale (QLS). ${ }^{22}$

We sought consent to interview each participant's family and from the family obtained collateral information on premorbid functioning, duration of prodrome and DUP.

With the Premorbid Adjustment Scale, ${ }^{23}$ we assessed each individual's premorbid social adjustment (PSA) during two discrete stages of their early life: age 5-11 (PSA1) and age 12-16 (PSA2). Because the time of life assessed by the PSA2 interview is often the age at onset of prodrome or psychosis, we used only PSA1 scores in our analyses.

Duration of untreated psychosis and duration of prodrome were measured using the Beiser scale. ${ }^{24}$ The individual and family were interviewed and a DUP obtained from each. When they disagreed, we came to a consensus figure based on the interviews and any sources of information available. When the participant did not consent to a family interview, we used the participant's interview and all other information. Onset of prodrome was defined as first noted deviation from the individual's normal premorbid functioning or the emergence of prodromal symptoms as described in the Beiser scale. Duration of prodrome was the time between the onset of prodromal symptoms and the onset of the first psychotic symptom. Duration of untreated psychosis was the period between the onset of the first psychotic symptom and the institution of antipsychotic treatment. Duration of untreated illness was the sum of the duration of prodrome and DUP.

\section{Follow-up assessments: 1999-2005}

During follow-up at 4 years (1999-2002) and 8 years (2003-2005), we repeated all presentation assessments except the Premorbid Adjustment Scale and the Beiser scale. We added the Strauss-Carpenter Level of Functioning Scale (SCLF), which allows separate evaluation of social and occupational functioning. ${ }^{25}$ During follow-up, as far as possible given the demands of tracing, each interviewer remained masked to all previous assessments. Masking to DUP and DUI was strictly maintained.

For positive, negative and disorganised symptom scores, we used the PANSS sub-scales recently validated by van der Gaag et al. ${ }^{26,27}$ Anyone who had scored no more than 3 on any of the 30 PANSS items over the previous month was said to be in remission; ${ }^{28}$ we used this definition of remission when reporting 4-year follow-up results. ${ }^{17}$

\section{Inclusion in the 8-year analyses}

At presentation 118 people were diagnosed with non-affective psychosis. Of these, 20 people $(16.9 \%)$ refused consent for family involvement in the study. We did not have PSA1 scores for this group and we could not include them in our primary analyses; any analysis of the relationship between DUP, DUI and outcome must control for premorbid adjustment, the key confounder. ${ }^{11}$ Of the remaining 98 people, 4 were known to have died by 8 -year follow-up. At either 4-year or 8-year follow-up, 15 people refused further involvement and 12 people could not be traced. Therefore, we had three full data-sets for 67 participants $(56.8 \%)$ and included them in the primary analyses. Fifty-one $(43.2 \%)$ people were non-completers and were not included.

In the event that primary analyses showed no relationship between PSA1 and outcome, we performed secondary analyses in which we did not control for premorbid adjustment. There were 77 participants in these analyses $(65.3 \%)$; 41 were excluded $(34.7 \%)$.

\section{Data analysis}

We explored any differences between the completer and noncompleter groups using univariate analyses. Because of positive skew, we log-transformed DUP and DUI to normalise them for analysis. We did not log-transform prodrome, which was also positively skewed, because the score for prodrome in 19 cases was zero and the log of zero is not calculable. Instead, we created a categorical prodrome variable: short (1 month or less), medium (1-12 months) and long (over 12 months).

We calculated the mean scores of all continuous outcome variables at 4 and 8 years, and compared mean 4 -year and 8 -year scores using paired-sample $t$-tests.

To identify independent predictors at presentation of 8-year outcome variables, we used linear or logistic regression modelling. When the outcome variable of interest was continuous (e.g. GAF, QLS), we built hierarchical linear regression models. We also used linear regression to identify predictors of change in continuous variables between 4 and 8 years. We built these models in a sequential chronological method described in a similar study. ${ }^{18}$ When the outcome variable of interest was dichotomous (e.g. remission), we used binary logistic regression modelling ('Enter' method). In linear regression, the $R^{2}$ change statistic indicates the magnitude of the relationship between the independent and dependent variable; its equivalent in logistic regression is the adjusted odds ratio (AOR). Variables considered as independent variables were: age, gender, PSA1, years in education, lifetime history of substance misuse, duration of prodrome, DUP, negative symptoms, positive symptoms, disorganised symptoms, insight and presentation GAF. In each regression model, we included as independent variables all items with at least a trend level unadjusted association $(P<0.10)$ with the dependent variable.

We repeated all regression analyses replacing DUP with DUI to establish whether including DUI rather than DUP improved the models. Given the high correlation between DUP and DUI (Spearman's rho=0.82, $P<0.001$ ), we did not include DUI and DUP in the same models. When DUP and DUI both contributed, in separate models, to a given outcome, we reported the better model. In linear regression, this was the model with the higher overall $R^{2}$ statistic; in logistic regression, that with the lower -2 $\log$ likelihood statistic.

In the event that DUP or DUI predicted a given outcome, we compared the means of that variable for long and short groups. For DUP, we made this division at three time points - 1 month, 3 months and 1 year - to identify precisely any clinically important cut-off point. We divided DUI at 6 months, 12 months and 2 years. 


\section{Results}

\section{Follow-up and characteristics of the sample}

The mean duration of follow-up at 4 years was 42.0 months (s.d.=8.9, median=42); mean follow-up at 8 years was 95.3 months (s.d. $=15.6$, median $=96$ ). Table 1 compares the characteristics of completers $(n=67)$ and non-completers $(n=51)$. Completers were younger at onset $(t=2.7, P=0.01)$ and more likely to be male $\left(\chi^{2}=9.6, P<0.01\right)$. One person was under 16 at onset and none were over 65 .

\section{Symptomatic outcome at 8 years}

Thirty-three people $(49.3 \%)$ were in remission. The mean positive symptom score was 11.6 (s.d.=6.1), the mean negative symptom score was 13.4 (s.d.=5.8) and the mean disorganised symptom score was 15.3 (s.d. $=5.8$ ); see Table 2 for sub-scale ranges.

\section{Psychosocial outcome at 8 years}

The mean GAF at 8 years was 64.1 (s.d.=18.6): 22 people $(32.8 \%)$ scored 50 or less, denoting serious functional impairment; 19 people $(28.3 \%)$ scored $51-70$, indicating moderate impairment; 9 people (13.4\%) scored 71-80, indicating mild impairment; and $17(25.4 \%)$ scored 81 or over, indicating no impairment.
The mean SCLF social score was 5.3 (s.d.=2.0): 22 people $(32.8 \%)$ scored 7 or 8 , indicating frequent social contacts and close relationships. The mean SCLF occupational score was 4.8 (s.d.=2.8): 23 people (34.3\%) scored 7 or 8 , indicating that they were competent or very competent at full-time work or education.

The mean QLS score was 84.0 (s.d. $=26.4$, median $=87$, range 25-124). In terms of independent living, 17 people (25.4\%) were living in unsupported accommodation; 44 people $(65.7 \%)$ were living with parents or other family; 5 (7.5\%) were in hostels or supported accommodation; and 1 person (1.5\%) was homeless.

\section{Change in outcome between 4 and 8 years}

Table 2 shows mean 4-year and 8-year scores, with paired-sample $t$-tests to detect significant changes. Overall, 29 people $(43.3 \%)$ were in remission at 4 years and $33(49.3 \%)$ at 8 years; a binomial test with the test proportion set at 0.433 showed that the improvement to 0.493 by 8 years was not significant $(P=0.18)$.

\section{Predictors at presentation of 8-year symptomatic outcome}

Remission was predicted by older age at onset $(\mathrm{AOR}=1.14,95 \%$ $\mathrm{CI}=1.04-1.25, \quad P<0.01)$ and shorter DUP $(\mathrm{AOR}=0.40,95 \%$ $\mathrm{CI}=0.17-0.92, P=0.03)$. When DUP was divided at 1 month, 9

\begin{tabular}{|c|c|c|}
\hline Variable & Completers & Non-completers \\
\hline \multicolumn{3}{|l|}{ Demographics } \\
\hline Age at onset, years: mean (s.d.) & $24.4(6.5)$ & $29.4(12.4)^{\star \star}$ \\
\hline Male, \% & 73.1 & $45.1^{* *}$ \\
\hline Education, years: mean (s.d.) & $13.7(2.7)$ & $12.9(2.6)$ \\
\hline \multicolumn{3}{|l|}{ Structured Clinical Interview for DSM-IV diagnosis } \\
\hline Schizophrenia/schizophreniform, \% & 89.6 & 80.4 \\
\hline \multicolumn{3}{|l|}{ Psychopathology } \\
\hline Positive symptoms score (range 1-55), mean (s.d.) & $22.8(5.4)$ & $23.7(6.4)$ \\
\hline Negative symptoms score (range 2-62), mean (s.d.) & $16.6(8.8)$ & $15.3(8.6)$ \\
\hline Disorganised symptoms score (range 10-70), mean (s.d.) & $25.4(8.3)$ & $24.4(8.3)$ \\
\hline Insight score (range 1-7), mean (s.d.) & $4.8(1.4)$ & $4.6(1.4)$ \\
\hline Lifetime substance misuse, \% & 38.9 & 25.5 \\
\hline \multicolumn{3}{|l|}{ Duration of untreated illness } \\
\hline Prodrome, months: mean (s.d.) & $30.5(40.5)$ & $25.7(38.3)$ \\
\hline Prodrome, months: median & 8.0 & 11.0 \\
\hline Duration of untreated psychosis, months: mean (s.d.) & $20.4(22.8)$ & $28.6(48.5)$ \\
\hline Duration of untreated psychosis, months: median & 12.0 & 11.0 \\
\hline \multicolumn{3}{|l|}{ Psychosocial functioning } \\
\hline Global Assessment of Functioning score, mean (s.d.) & $22.5(9.0)$ & $22.5(8.1)$ \\
\hline Premorbid adjustment, ${ }^{\mathrm{a}}$ mean (s.d.) & $12.2(4.3)$ & $10.8(4.0)^{\mathrm{b}}$ \\
\hline
\end{tabular}

\begin{tabular}{|c|c|c|c|c|c|}
\hline Variable & Range $^{a}$ & 4 years, mean & 8 years, mean & $t$-test & $P$ \\
\hline \multicolumn{6}{|l|}{ Psychosocial } \\
\hline GAF & 0-100 & 59.6 & 64.1 & 2.4 & 0.02 \\
\hline SCLF social & $0-8$ & 6.0 & 5.3 & 2.5 & 0.01 \\
\hline SCLF occupational & $0-8$ & 5.3 & 4.8 & 1.5 & 0.14 \\
\hline QLS, total & $0-126$ & 83.4 & 84.0 & 0.23 & 0.82 \\
\hline \multicolumn{6}{|l|}{ Symptomatic } \\
\hline Positive symptoms & $1-55$ & 12.1 & 11.6 & 0.83 & 0.41 \\
\hline Negative symptoms & $2-62$ & 16.6 & 13.4 & 5.0 & $<0.001$ \\
\hline Disorganised symptoms & $7-70$ & 16.9 & 15.3 & 3.5 & 0.001 \\
\hline
\end{tabular}


$(82 \%)$ of the short DUP group $(n=11)$ were in remission, but of those in the long DUP group $(n=56), 24(42.9 \%)$ were in remission $\left(\chi^{2}=5.6, P=0.02\right)$.

The only predictor at presentation of positive symptoms at 8 years was DUP $\left(\mathrm{R}^{2}\right.$ change $\left.=0.12, P<0.01\right)$. The short DUP group had fewer positive symptoms than the long DUP group when the cut-off was made at 1 month $(8.4 v .12 .2, t=3.1$, $P<0.01)$ or 3 months $(t=2.7, P=0.01)$. With a cut-off of 1 year, there was no difference.

Negative symptoms were predicted by DUI $\left(R^{2}\right.$ change $=0.08$, $P=0.01)$. With DUI divided at 2 years, the short DUI group scored 4.4 points fewer than the long DUI group $(F=11.1, P=0.001)$. Disorganised symptoms were predicted by younger age at onset $\left(R^{2}\right.$ change $=0.14, P<0.01)$ and impaired insight $\left(\mathrm{R}^{2}\right.$ change $=0.06$, $P=0.03)$.

\section{Predictors of 8-year symptomatic outcomes in secondary regression analyses}

Upon removing PSA1 as an independent variable, the group included in analyses $(n=77)$ was no different from those excluded $(n=41)$ with respect to age at onset, but completers were more likely to be male $\left(\chi^{2}=4.0, P=0.05\right)$. In secondary analyses, remission was predicted by shorter DUP (AOR $=0.43,95 \% \mathrm{CI}=0.22-$ $0.87, P=0.02)$ and female gender $(\mathrm{AOR}=3.4,95 \% \mathrm{CI}=1.2-9.8$, $P=0.02$ ). There were no other differences between primary and secondary analyses.

\section{Predictors at presentation of 8-year psychosocial outcome}

Table 3 shows the trend level and significant unadjusted associations between presentation variables and 8-year GAF. The best regression model with GAF as dependent variable accounted for $40 \%$ of its variance and included DUI not DUP. The construction of this model from the variables in Table 3 is shown in Table 4. As shown, higher GAF was predicted by older age at onset, shorter DUI and preserved insight. With DUI divided at 2 years, the short DUI group scored 20 points higher than the long DUI group, indicating considerably better functioning (74.5 v. 55.1; $F=24.7$, $P<0.001)$.

Better SCLF social functioning was predicted by shorter DUP $\left(\mathrm{R}^{2}\right.$ change $\left.=0.15, P<0.01\right)$, preserved insight $\left(\mathrm{R}^{2}\right.$ change $=0.11$, $P<0.01)$, older age at onset $\left(\mathrm{R}^{2}\right.$ change $\left.=0.13, P=0.001\right)$ and female gender $\left(\mathrm{R}^{2}\right.$ change $\left.=0.04, P=0.04\right)$ (total $\left.\mathrm{R}^{2}=0.43\right)$. Better SCLF occupational functioning was associated with older age at onset $\left(\mathrm{R}^{2}\right.$ change $\left.=0.16, \quad P=0.001\right)$ and shorter DUI $\left(\mathrm{R}^{2}\right.$ change $=0.07, P=0.02$ ). Independent living correlated with older age at onset $\left(\mathrm{R}^{2}\right.$ change $\left.=0.16, P<0.001\right)$.

The model with QLS total as dependent variable explained $42 \%$ of QLS variance. Higher quality of life was predicted by longer duration of education $\left(\mathrm{R}^{2}\right.$ change $\left.=0.14, P<0.01\right)$, more insight $\left(\mathrm{R}^{2}\right.$ change $\left.=0.08, P=0.02\right)$, older age $\left(\mathrm{R}^{2}\right.$ change $=0.14$, $P<0.01)$ and shorter DUI $\left(\mathrm{R}^{2}\right.$ change $\left.=0.05, P=0.03\right)$. With DUI divided at 2 years, the short DUI group had a mean QLS of 96.1 against a mean of 73.6 for the long DUI group $(F=17.3$, $P<0.001)$. None of these models changed in secondary regression analyses.

\section{Predictors of change in outcome between 4 and 8 years}

Duration of prodrome predicted change in negative symptoms, with shorter prodrome predicting improvement $\left(\mathrm{R}^{2}\right.$ change $=0.06$, $P=0.04$ ). There were no predictors at presentation of change in likelihood of remission or other symptom dimensions. Shorter
Table 3 Unadjusted associations, with $P<0.10$, between presentation variables considered for inclusion in stepwise regression models and Global Assessment of Functioning at 8 years

\begin{tabular}{|cc|} 
Variable & $P$ \\
Duration of untreated illness & $<0.001$ \\
\hline Duration of untreated psychosis & 0.001 \\
\hline Age at onset & 0.001 \\
\hline Premorbid social adjustment: age 5-11 (PSA1) & 0.01 \\
\hline Time spent in education & 0.01 \\
\hline Insight & 0.10 \\
\hline
\end{tabular}

Table 4 Construction of the hierarchical stepwise linear

regression model with 8-year Global Assessment of

Functioning as dependent variable using variables in Table 3 Step Independent variable added Model $\mathrm{R}^{2 \mathrm{a}} \quad \mathrm{R}^{2}$ change $\quad P$

\begin{tabular}{|clccc|}
\hline 1 & Age at onset & 0.17 & 0.17 & $<0.001$ \\
\hline 2 & + Years in education + PSA1 & 0.17 & - & NS \\
\hline 3 & + Duration of untreated illness & 0.35 & 0.19 & $<0.001$ \\
\hline 4 & + PANSS insight & 0.35 & 0.06 & 0.02 \\
\hline
\end{tabular}

NS, not significant; PANSS, Positive and Negative Syndrome Scale. PSA1, Premorbid NS, not significant; PANSS, Positive and Negative Syndrome Scale. PSA1, Premorbid
social adjustment: age 5-11.

a. Model $R^{2}$ is less than the sum of $R^{2}$ change in steps 1,3 and 4 because of rounding.

DUI predicted improvement in GAF score between 4 and 8 years $(\triangle \mathrm{GAF})$, when DUI was included in the regression model as a dichotomous variable divided at 2 years. Using log-transformed DUI, no predictors of $\triangle \mathrm{GAF}$ were found.

Duration of untreated illness at 2 years was the only presentation variable to predict $\triangle \mathrm{GAF}\left(\mathrm{R}^{2}\right.$ change $\left.=0.10, P=0.01\right)$. Global Assessment of Functioning for those with a DUI of 2 years or less improved by 9.7 points, while for those with a longer DUI it improved by 0.1 points $(F=7.1, P=0.01)$. Figure 1 shows mean GAF scores at 0,4 and 8 years for the short and long DUI groups.

Change in QLS also correlated with DUI at 2 years only $\left(\mathrm{R}^{2}\right.$ change $=0.08, P=0.02$ ). The QLS of the short DUI group improved by 6.7 points but that of the long DUI group deteriorated by 4.6 points $(F=6.0, P=0.02)$.

We considered the possibility that total duration of illness, rather than DUI, accounted for differential psychosocial progression after 4-year assessment; participants with shorter durations of illness might not by then have reached a point of chronic stability relative to those with longer duration of illness. We rebuilt our models replacing DUI with total duration of illness, which we calculated by adding DUI to the duration of follow-up at 4 -year assessment. Total illness duration (mean $=88.0$ months, median= 75 months) did not correlate with GAF or QLS change.

There were no predictors of 4 - to 8 -year change in SCLF.

\section{Discussion}

\section{Eight-year outcome in first-episode non-affective psychosis}

This first-episode psychosis cohort exhibited a variety of outcomes at 8 years. Psychosocially, 39\% were functioning at a level that indicated social recovery, but a third had serious functional difficulties. Quality of life scores were mid- to high range. The proportion living independently was in keeping with the results of the Nottingham study at 13 -year follow-up. ${ }^{29}$ Symptomatically, 


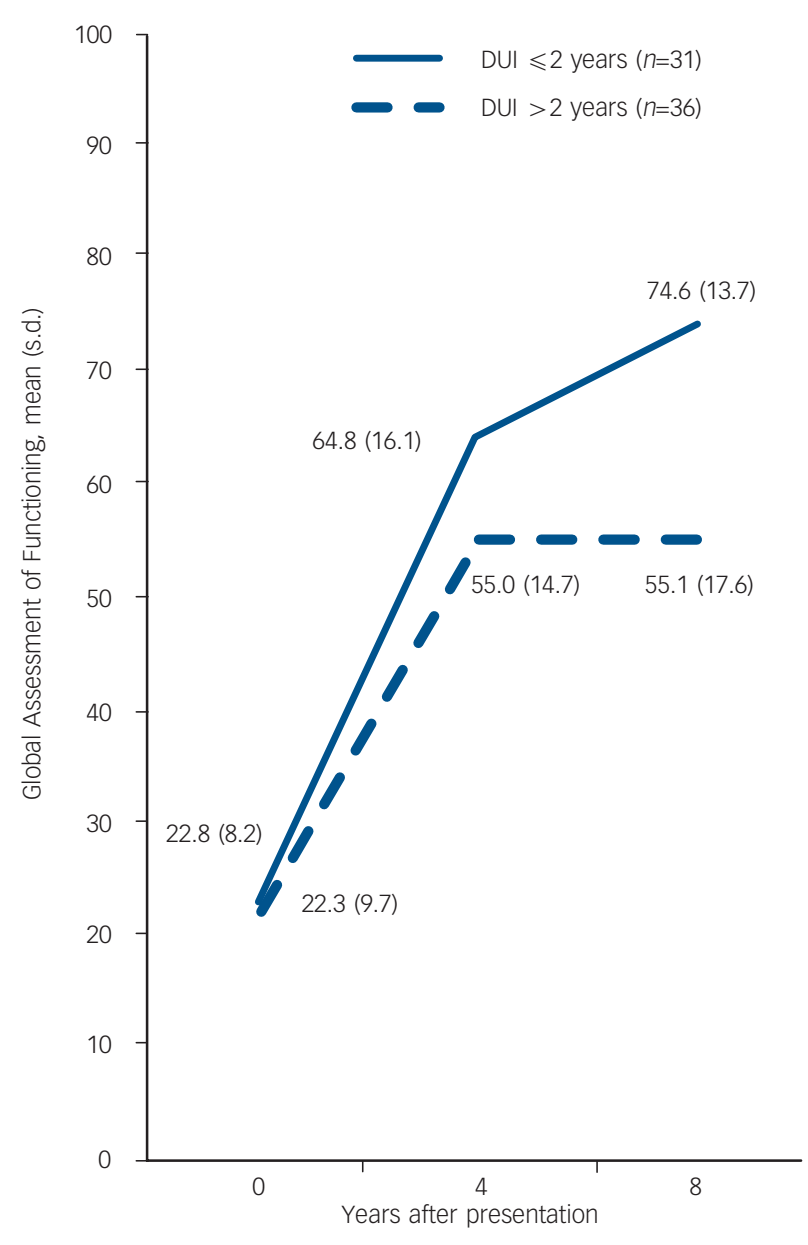

Fig. 1 Mean Global Assessment of Functioning by duration of untreated illness (DUI) group at 0, 4 and 8 years. half of our cohort were in remission and half remained symptomatic.

\section{Change in outcome between 4 and 8 years}

Between 4 and 8 years, GAF functioning slightly improved. On the SCLF scale occupational functioning did not change and social functioning marginally worsened. Symptomatically, the proportion in remission did not change. Negative and disorganised symptom scores improved but positive symptoms did not change.

The magnitude of change of any variable, as a proportion of its range, was small, and we suggest that any change for the cohort as a whole was of statistical rather than clinical significance. Thus, for the cohort as a whole, we do not contradict previous reports of stability after the early course of psychosis. ${ }^{6,7}$ However, there is a nuance in this apparent overall stability. Although GAF and QLS both essentially stabilised after 4 years for the cohort as a whole, it was possible to identify, at presentation, a group that would continue to recover beyond the critical period and a group that would not. For the former group, the hypothesis that there is a plateau of recovery post-critical period was not supported.

It was DUI that determined whether recovery would continue. With respect to functioning, there was no separation by GAF score between long and short DUI groups at presentation; there was a difference of 10 points at 4 years and at 8 years the difference was 20 points. Quality of Life Scale scores, meanwhile, deteriorated after 4 years for the long DUI group and improved for the short DUI group. These relationships were not confounded. There was no evidence of a diminishing effect of untreated illness with time.

\section{Duration of untreated psychosis, DUI and 8-year outcome}

Duration of untreated psychosis emerged as an independent predictor of 8-year outcome in non-affective psychosis. It predicted remission, positive symptoms and social functioning. It did not predict GAF, QLS, occupational functioning or independent living.

Our finding that DUP longitudinally predicted symptomatic and psychosocial outcomes disagrees with the findings of several authors. $^{9,11,12,15}$ It is, though, in keeping with the few other longitudinal studies that have measured the effect of DUP for 2 years or longer after presentation. ${ }^{10,14,17,18}$ Regarding a DUP cut-off, symptom scores were lower if DUP was under 3 months, and remission more likely only if DUP was under 1 month.

Duration of untreated illness correlated more closely with psychosocial outcome than DUP. In this, our results paralleled those of Keshavan et al, who, defining DUI as we did, found that it predicted GAF and SCLF at 2-year follow-up. ${ }^{30}$ The association between DUI and outcome in their study persisted after controlling, as in our study, for premorbid adjustment. We found a 2year cut-off for DUI consistently to correlate with 8-year morbidity.

It is not surprising that DUI should be a stronger predictor of psychosocial outcome than DUP; DUP is a stronger predictor of positive symptoms than DUI, while DUI is a stronger predictor of negative symptoms than DUP and negative symptoms are more strongly associated with psychosocial outcome than positive symptoms. ${ }^{31-33}$ What may be surprising is that the effect of DUI on outcome is reported rarely relative to that of DUP. ${ }^{13,30}$

\section{Strengths and limitations}

The main strengths of this study are its design, sampling and length of follow-up. We identified all in-patients and out-patients referred with psychosis to a geographically defined catchment area service over a period of 4 years. There were no initial refusals to participate. In terms of duration alone, there have been longer follow-up studies of outcome from the time of first presentation with psychosis. ${ }^{6,7,14,15,31-34}$ However, as a prospective study capable of examining the effect of DUP and DUI on outcome, independent of confounders, our duration of follow-up is equalled only by the EPPIC study. ${ }^{17}$ Although the Munich study ${ }^{14}$ reported that it controlled for premorbid adjustment, it measured adjustment in adulthood, and what was rated as poor premorbid adjustment may have been prodromal or early psychotic symptomatology. The 15-year Dutch study ${ }^{15}$ did not measure DUP systematically. Neither study discussed DUI.

Our principal weakness is that of the 118 people recruited with first-episode non-affective psychosis, 51 were not included in the primary analyses. Our ratio of completers to non-completers was comparable with that of the EPPIC cohort at 8 years, ${ }^{17}$ the OPUS cohort at 5 years, ${ }^{35}$ and the Calgary cohort at 2 years, ${ }^{10}$ but the numbers in our primary analyses may have exposed our results to type II error. A related issue is selection bias: the participants included in our primary analyses were more likely than those excluded to be male and were younger at onset. Both male gender and young onset predict poor outcome, ${ }^{36}$ and had we included the female and later-onset participants who were excluded from the 
primary analyses, our reported outcomes at 8 years might have been more favourable.

Our definition of remission ${ }^{17,27}$ was not the definition proposed by the Remission in Schizophrenia Working Group (RSWG). ${ }^{37}$ We did not use these criteria because they were not published until 8-year data collection was virtually completed, and it was not possible retrospectively to apply them. Had we used the RSWG criteria, we may have found a lower rate of remission, as the RSWG criteria require a longer symptom-free period. The definition of remission used in our paper may have advantages over the RSWG definition in that it allows for a broader conceptualisation of the symptom dimensions that are important in psychosis. $^{38}$

A further limitation is that our data did not allow detailed assessment of the course of illness. We assessed participants at three time points and related variables at these time points to one another, but we did not examine course in the intervening periods (e.g. chronic $v$. episodic), as previous longitudinal firstepisode psychosis studies did. ${ }^{7,15,39}$

Additionally, we did not consider the type of onset of psychosis: acute, sub-acute or insidious. Type of onset relates to the period of time over which the participant develops frank psychotic symptoms, ${ }^{15}$ while DUP may include this period as well as the time between the emergence of frank symptoms and the institution of adequate treatment. Insidious onset predicts poor prognosis. ${ }^{40}$ As insidious onset and longer DUP may be related, the relationship between DUP and outcome may be confounded by insidious onset. Some longitudinal first-episode psychosis studies that have controlled both for type of onset and DUP have found that insidious onset, rather than DUP, predicts outcome. $^{15,40}$

\section{The critical period hypothesis, DUI and early intervention}

Our median DUP was 12 months, so 4-year assessments took place a median of 4.5 years after the onset of psychosis. We took this as a reasonable point of demarcation for the end of the critical period. Although 2-3 years after onset was the duration suggested in the original paper, ${ }^{1}$ other authors extended it to 5 years; ${ }^{41,42}$ indeed, years before the DUP era, Manfred Bleuler posited 5 years as the point beyond which outcomes stabilise in schizophrenia. ${ }^{43}$

The hypothesis that outcome stabilises after the end of the critical period was not supported. The main reason was not the marginal changes among the cohort as a whole but rather the marked improvement in functioning among a sub-cohort identifiable at presentation: the group with DUI of 2 years or less. The second premise of the critical period hypothesis was upheld. Duration of untreated psychosis predicted 8-year outcome after controlling for confounders; thus the predictive power of DUP was not an epiphenomenon.

As only one of the central premises of the critical period hypothesis was supported, and DUP was arguably not as important in predicting outcome as DUI, which was not mentioned in the original critical period paper, ${ }^{1}$ do our findings weaken the case for early detection and intervention in psychosis? We conclude not, for four reasons.

First, although we did not find overall stability beyond the critical period, neither did we find deterioration; we found either stability or continued recovery. Had we found that deterioration ensued after 4 years, that would have undermined the case for early intervention, as recovery attained as a result of intervention during the critical period could not be expected to endure. Second, recovery after the critical period occurred for those with a short DUI, the sum of DUP and prodrome; continued recovery would be more likely among those detected early. Third, DUI independently predicted 8-year outcome. These findings support DUI reduction and maximal DUI reduction requires detection of impending cases of psychosis during the prodrome; the critical period could be extended to include the prodrome as well as early psychosis. Certainly, our results underscore the clinical potential of ultra-high risk (prodromal) research. ${ }^{44,45}$ However, although prodromal research is 'increasing in maturity and sophistication, ${ }^{, 6}$ the case for prodromal detection is not yet strong enough to support widespread development of ultra-high risk services. Meanwhile, the practical strategy for reducing DUI is early detection and intervention in established psychosis. ${ }^{47}$ The fourth reason that our findings do not weaken the case for early intervention is perhaps the most obvious: longer DUP independently predicted adverse outcomes 8 years after presentation. Short DUP groups had an advantage over long DUP groups in terms of remission, symptom severity and social functioning.

The decade since the critical period hypothesis was published ${ }^{1}$ has seen evidence mount of harm done by untreated psychosis in the short term ${ }^{48,49}$ and medium term. ${ }^{10,17}$ What has not been clearly shown is that early intervention ameliorates this harm, ${ }^{50}$ and we have not shown here that DUP reduction would improve 8 -year outcome. Long DUP could yet be a proxy for insidious onset or some other unmodifiable determinant of outcome as yet not considered. Ultimately, this question will be answered by long-term randomised controlled trials of early intervention. While we await such trials, we cautiously propose that our findings show that a shorter DUP brings with it benefits that extend well beyond the critical period.

\section{Niall Crumlish, MRCPsych, Stanley Research Unit, Cluain Mhuire Family Centre, St John of God Adult Psychiatric Service, and Department of Psychiatry, Trinity College, Dublin; Peter Whitty, MD, MRCPsych, Mary Clarke, MD, MRCPI, MRCPsych, Stephen Browne, MD, MRCPsych, Moayyad Kamali, MRCPsych, Maurice Gervin, MRCPSych, Stanley Research Unit, Cluain Mhuire Family Centre, St John of God Adult Psychiatric Service and Department of Psychiatry, University College, Dublin; Orfhlaith McTigue, MRCPsych, Stanley Research Unit, Cluain Mhuire Family Centre, St John of God Adult Psychiatric Service, Dublin, Anthony Kinsella, FIS, DELTA/DETECT Early Intervention in Psychosis Services, Dun Laoghaire Co. Dublin; John L Waddington, DSC, Stanley Research Unit, Department of Molecular and Cellular Therapeutics, Royal College of Surgeons in Ireland, Dublin; Conall Larkin, FRCPI, FRCPsych, Eadbhard O'Callaghan, MD, DSC, FRCPI, FRCPsych, Stanley Research Unit, Cluain Mhuire Family Centre, St John of God Adult Psychiatric Service, Department of Psychiatry, University College, Dublin, and DELTA/ DETECT Early Intervention in Psychosis Services, Blackrock, Co. Dublin, Ireland.}

Correspondence: Eadbhard O'Callaghan, DELTA/DETECT Early Intervention in Psychosis Services, Block 5, Blackrock Business Park, Carysfort Avenue, Blackrock, Co. Dublin, Ireland. Email: eadbhard@gmail.com.

First received 17 Dec 2007, final revision 25 Jun 2008, accepted 8 Jul 2008

\section{Acknowledgements}

We thank all the participants and their families. Supported by the Stanley Medical Research Institute, Health Research Board and Science Foundation, Ireland.

\section{References}

1 Birchwood M, Todd $\mathrm{P}$, Jackson, C. Early intervention in psychosis: the critical period hypothesis. Br J Psychiatry 1998; 172 (suppl 33): s53-9.

2 Craig TK, Garety P, Power P, Rahaman N, Colbert S, Fornells-Ambrojo M et al. The Lambeth Early Onset (LEO) Team: a randomised controlled trial of the effectiveness of specialised care for early psychosis. BMJ 2004; 329 : 1067-70.

3 Edwards J, Harris MG, Bapat S. Developing services for first-episode psychosis and the critical period. Br J Psychiatry 2005; 187 (suppl 48): s91-7.

4 Petersen L, Nordentoft $\mathrm{M}$, Jeppesen $\mathrm{P}$, Øhlenschaeger J, Thorup A, Christensen TØ, et al. Improving 1-year outcome in first-episode psychosis. OPUS trial. Br J Psychiatry 2005; 187 (suppl 48): s98-103.

5 Pelosi AJ, Birchwood M. Is early intervention a waste of valuable resources? Br J Psychiatry 2003; 182: 196-8. 
6 Carpenter W, Strauss J. The prediction of outcome in schizophrenia, IV: eleven year follow-up of the Washington IPSS cohort. J Nerv Ment Dis 1991: 179: $517-25$.

7 Eaton WW, Thara R, Federman B, Melton B, Liang KY. Structure and course of positive and negative symptoms in schizophrenia. Arch Gen Psychiatry 1995; 52: $127-34$

8 Browne S, Clarke M, Gervin M, Waddington JL, Larkin C, O'Callaghan E. Determinants of quality of life at first presentation with schizophrenia. Br J Psychiatry 2000; 176: 173-6.

9 Ho BC, Andreasen NC, Flaum M, Nopoulos P, Miller D. Untreated initia psychosis: its relation to quality of life and symptom remission in firstepisode schizophrenia. Am J Psychiatry 2000; 157: 808-15.

10 Addington J, van Mastrigt S, Addington D. Duration of untreated psychosis: impact on 2-year outcome. Psychol Med 2004; 34: 277-84.

11 Verdoux $H$, Liraud $F$, Bergey $C$, Assens $F$, Abalan $F$, van Os J. Is the association between duration of untreated psychosis and outcome confounded? A two year follow-up of first-admitted patients. Schizophr Res 2001; 49: 231-41.

12 Craig TJ, Bromet EJ, Fennig S, Tanenberg-Karant M, Lavelle J, Galambos N. Is there an association between duration of untreated psychosis and 24-month clinical outcome in a first-admission series? Am J Psychiatry 2000; 157: 60-6.

13 Malla A, Norman R, Schmitz N, Manchanda R, Béchard-Evans L, Takhar J, et al. Predictors of rate and time to remission in first-episode psychosis: a two-year outcome study. Psychol Med 2006; 36: 649-58.

14 Bottlender R, Sato $T$, Jäger $M$, Wegener $U$, Wittmann J, Strauss $A$, et al. The impact of duration of untreated psychosis prior to first psychiatric admission on the 15-year outcome in schizophrenia. Schizophr Res 2003; 62: 37-44.

15 Wiersma D, Nienhuis FJ, Slooff CJ, Giel R. Natural course of schizophrenic disorders: a 15-year follow-up of a Dutch incidence cohort. Schizophr Bull 1998; 24: 75-85.

16 Johnstone EC, Crow TJ, Johnson AL, MacMillan JF. The Northwick Park Study of first episodes of schizophrenia. I. Presentation of the illness and problems relating to admission. Br J Psychiatry 1986; 148: 115-20.

17 Clarke $M$, Whitty $P$, Browne $S$, McTigue $O$, Kamali $M$, Gervin $M$, et al. Untreated illness and outcome of psychosis. Br J Psychiatry 2006; 189 235-40.

18 Harris MG, Henry LP, Harrigan SM, Purcell R, Schwartz OS, Farrelly SE, et al The relationship between duration of untreated psychosis and outcome: an eight-year prospective study. Schizophr Res 2005; 79: 85-94.

19 American Psychiatric Association. Diagnostic and Statistical Manual of Mental Disorder (4th edn) (DSM-IV). APA, 1994

20 Kay SR, Fissbein A, Opler LA. The positive and negative syndrome scale for schizophrenia. Schizophr Bull 1987; 13: 261-76.

21 First MB, Spitzer RL, Gibbon M, Williams JB. Structured Clinical Interview fo DSM-IV Axis I Disorders. New York State Psychiatric Institute, 1995.

22 Heinrichs DW, Hanlon TG, Carpenter WT, Jr. The Quality of Life Scale: an instrument for rating the schizophrenic deficit syndrome. Schizophr Bull 1984; 10: 388-98.

23 Foerster A, Lewis S, Owen M, Murray R. Premorbid adjustment and personality in psychosis. Effects of sex and diagnosis. Br J Psychiatry 1991 158: 171-6.

24 Beiser M, Erickson D, Fleming JA, Iacono WG. Establishing the onset of psychotic illness. Am J Psychiatry 1993; 150: 1349-54.

25 Strauss JS, Carpenter WT, Jr. The prediction of outcome in schizophrenia. II. Relationships between predictor and outcome variables: a report from the WHO International Pilot Study of Schizophrenia. Arch Gen Psychiatry 1974; 31: $37-42$.

26 van der Gaag $\mathrm{M}$, Hoffman $\mathrm{T}$, Remijsen $\mathrm{M}$, Hijman $\mathrm{R}$, de Haan $\mathrm{L}$, van Meijel $\mathrm{B}$ et al. The five-factor model of the Positive and Negative Syndrome Scale II: a ten-fold cross-validation of a revised model. Schizophr Res 2006; 85: 280-7.

27 van der Gaag M, Cuijpers A, Hoffman T, Remijsen M, Hijman R, de Haan L, et al. The five-factor model of the Positive and Negative Syndrome Scale I: Confirmatory factor analysis fails to confirm 25 published five-factor solutions. Schizophr Res 2006; 85: 273-9.
28 Larsen TK, Moe LC, Vibe-Hansen L, Johannessen JO. Premorbid functioning versus duration of untreated psychosis in 1 year outcome in first-episode psychosis. Schizophr Res 2000; 45: 1-9.

29 Mason P, Harrison G, Glazebrook C, Medley I, Dalkin T, Croudace T. Characteristics of outcome in schizophrenia at 13 years. Br J Psychiatry 1995; 167: 596-603

30 Keshavan MS, Haas G, Miewald J, Montrose DM, Reddy R, Schooler NR, et al. Prolonged untreated illness duration from prodromal onset predicts outcome in first episode psychoses. Schizophr Bull 2003; 29 . 757-69.

31 Munk-Jørgensen $P$, Mortensen PB. Schizophrenia: a 13-year follow-up. Diagnostic and psychopathological aspects. Acta Psychiatr Scand 1989; 79: 391-9.

32 Breier A, Schreiber JL, Dyer J, Pickar D. National Institute of Mental Health longitudinal study of chronic schizophrenia. Prognosis and predictors of outcome. Arch Gen Psychiatry 1991; 48: 239-46.

33 Fenton WS, McGlashan TH. Natural history of schizophrenia subtypes. II. Positive and negative symptoms and long-term course. Arch Gen Psychiatry 1991; 48: 978-86.

34 an der Heiden W, Hafner $\mathrm{H}$. The epidemiology of onset and course of schizophrenia. Eur Arch Psychiatry Clin Neurosci 2000; 250: 292-303.

35 Nordentoft $\mathrm{M}$, Jeppesen $\mathrm{P}$, Bertelsen $\mathrm{M}$, LeQuack $\mathrm{P}$, Abel MB, Thorup A, et al. The association between premorbid functioning, duration of untreated psychosis and outcome among patients with first-episode schizophrenia spectrum psychosis. Eur Arch Psychiatry Clinical Neurosci 2007; 257 (suppl 1): 7.

36 Davidson L, McGlashan TH. The varied outcomes of schizophrenia. Can J Psychiatry 1997; 42: 34-43.

37 Andreasen NC, Carpenter WT Jr, Kane JM, Lasser RA, Marder SR, Weinberger DR. Remission in schizophrenia: proposed criteria and rationale for consensus. Am J Psychiatry 2005; 162: 441-9.

38 Steel C, Garety PA, Freeman D, Craig E, Kuipers E, Bebbington P, et al. The multidimensional measurement of the positive symptoms of psychosis. Int J Methods Psychiatr Res 2007; 16: 88-96.

39 Thara R. Twenty-year course of schizophrenia: the Madras Longitudinal Study. Can J Psychiatry 2004; 49: 564-9.

40 Röpcke B, Eggers C. Early-onset schizophrenia: a 15-year follow-up. Eur Child Adolesc Psychiatry 2005; 14: 341-50.

41 Garety P, Jolley S. Early intervention in psychosis. Psych Bull 2000; 24: 321-3.

42 McGorry PD. The recognition and optimal management of early psychosis: an evidence-based reform. World Psychiatry 2002; 1: 76-83.

43 Bleuler M. The Schizophrenic Disorders: Long-Term Patient and Family Studies. Yale University Press, 1978.

44 McGlashan T. Commentary. Progress, issues and implications of prodromal research: an inside view. Schizophr Bull 2003; 29: 851-8.

45 Ruhrmann S, Bechdolf A, Kühn KU, Wagner M, Schultze-Lutter F, Janssen B, et al. Acute effects of treatment for prodromal symptoms for people putatively in a late initial prodromal state of psychosis. Br J Psychiatry 2007; 191 (suppl 51): s88-95.

46 Cannon TD, Cornblatt B, McGorry P. Editors' introduction: the empirical status of the ultra-high risk (prodromal) research paradigm. Schizophr Bull 2007; 33: 661-4.

47 Melle I, Larsen TK, Haahr U, Friis S, Johannessen JO, opjordsmoen S, et al. Reducing the duration of untreated first-episode psychosis: effects on clinical presentation. Arch Gen Psychiatry 2004; 61: 143-50.

48 Marshall M, Lewis S, Lockwood A, Drake R, Jones $\mathrm{P}$, Croudace $\mathrm{T}$. Association between duration of untreated psychosis and outcome in cohorts of firstepisode patients. Arch Gen Psychiatry 2005; 62: 975-83.

49 Perkins DO, Gu H, Boteva K, Lieberman JA. Relationship between duration of untreated psychosis and outcome in first-episode schizophrenia: a critical review and meta-analysis. Am J Psychiatry 2005; 162: 1785-804.

50 Marshall M, Rathbone J. Early intervention for psychosis. Cochrane Database Syst Rev 2006; 4: CD004718. 